Article

\title{
Structural and Optical Properties of Luminescent Copper(I) Chloride Thin Films Deposited by Sequentially Pulsed Chemical Vapour Deposition
}

\author{
Richard Krumpolec ${ }^{1}$, Tomáš Homola ${ }^{1} \mathbb{D}$, David C. Cameron ${ }^{1, *} \mathbb{B}$, Josef Humlíček ${ }^{2}$, \\ Ondřej Caha ${ }^{2}$, Karla Kuldová ${ }^{3}\left(\mathbb{D}\right.$, Raul Zazpe ${ }^{4,5}$ (D) Jan Přikryl ${ }^{4}$ and Jan M. Macak ${ }^{4,5}$ \\ 1 R \& D Center for Low-Cost Plasma and Nanotechnology Surface Modifications (CEPLANT), Department of \\ Physical Electronics, Faculty of Science, Masaryk University, Kotlářská 267/2, 61137 Brno, Czech Republic; \\ 235947@mail.muni.cz (R.K.); homola.tomas@gmail.com (T.H.) \\ 2 Department of Condensed Matter Physics, Masaryk University, Kotlářská 267/2, \\ 61137 Brno, Czech Republic; humlicek@sci.muni.cz (J.H.); caha@monoceros.physics.muni.cz (O.C.) \\ 3 Institute of Physics of the Czech Academy of Sciences, v.v.i., Cukrovarnická 10, \\ 16200 Prague 6, Czech Republic; kuldova@fzu.cz \\ 4 Centre of Materials and Nanotechnologies, Faculty of Chemical Technology, University of Pardubice, Nám. \\ Čs. Legií 565, 53002 Pardubice, Czech Republic; Raul.Zazpe@upce.cz (R.Z.); Jan.Prikryl@upce.cz (J.P.); \\ jan.macak@upce.cz (J.M.M.) \\ 5 Central European Institute of Technology, Brno University of Technology, Purkyňova 123, \\ 61200 Brno, Czech Republic \\ * Correspondence: dccameron@mail.muni.cz; Tel.: +420-549-49-1411
}

Received: 31 August 2018; Accepted: 15 October 2018; Published: 18 October 2018

\begin{abstract}
Sequentially pulsed chemical vapour deposition was used to successfully deposit thin nanocrystalline films of copper(I) chloride using an atomic layer deposition system in order to investigate their application to UV optoelectronics. The films were deposited at $125{ }^{\circ} \mathrm{C}$ using [Bis(trimethylsilyl)acetylene](hexafluoroacetylacetonato)copper(I) as a $\mathrm{Cu}$ precursor and pyridine hydrochloride as a new $\mathrm{Cl}$ precursor. The films were analysed by XRD, X-ray photoelectron spectroscopy (XPS), SEM, photoluminescence, and spectroscopic reflectance. Capping layers of aluminium oxide were deposited in situ by ALD (atomic layer deposition) to avoid environmental degradation. The film adopted a polycrystalline zinc blende-structure. The main contaminants were found to be organic materials from the precursor. Photoluminescence showed the characteristic free and bound exciton emissions from $\mathrm{CuCl}$ and the characteristic exciton absorption peaks could also be detected by reflectance measurements.
\end{abstract}

Keywords: vapour deposition; copper chloride; characterization; optical properties; XPS; crystal structure

\section{Introduction}

Copper(I) chloride $(\mathrm{CuCl})$ is a wide-bandgap, I-VII ionic semiconductor. $\gamma-\mathrm{CuCl}$ with zinc blende structure, which is stable below $407^{\circ} \mathrm{C}$, has a direct bandgap with $E_{\mathrm{g}}=3.395 \mathrm{eV}$ at $4 \mathrm{~K}$ [1]. It has a high exciton binding energy of $\sim 190 \mathrm{meV}$ [2], which is higher than both $\mathrm{GaN}(25 \mathrm{meV})$ [3] or $\mathrm{ZnO}(60 \mathrm{meV})$ [4]. $\mathrm{CuCl}$ has been investigated for some time for its application to optoelectronic devices [5-8]. The high binding energy gives the possibility of stable, room temperature, UV emission which, together with high biexciton binding energies, enables optoelectronic effects such as bistability and four-wave mixing with the potential for new short wavelength devices $[9,10]$.

In order to use $\mathrm{CuCl}$ in optoelectronic devices it has to be deposited in thin films or in arrays of nanoparticles. Thin films of $\mathrm{CuCl}$ have been deposited by thermal evaporation, molecular beam 
epitaxy, and magnetron sputtering [11-13]. Arrays of nanoparticles of $\mathrm{Cu}$ halides have been produced in a matrix of glass, silicon, or organic compounds by gas or liquid phase methods, typically in a three dimensional form [6,14-17] but the size of the crystallites has been difficult to control. Atomic layer deposition (ALD) has recently been shown to be able to produce two-dimensional nanocrystalline arrays of $\mathrm{CuCl}$ on substrates and the size and distribution of the crystallites could be controlled by the parameters of the deposition process $[18,19]$. These films have shown the crystal structure of $\gamma-\mathrm{CuCl}$ and demonstrated the luminescent and optical characteristics typical of $\mathrm{CuCl}$. One important feature of $\mathrm{CuCl}$ is that it is sensitive to moisture in its environment. Films of $\mathrm{CuCl}$ will hydrolyse to oxy- or hydroxy-halides after a short time and they need hermetic protection for long-term stability. Successful encapsulation by spun-on organic materials such as polysilsesquioxanes and cycloolefin copolymers has proved successful while plasma-enhanced chemical vapour deposition of $\mathrm{SiO}_{2}$ has not provided adequate encapsulation [20]. These spun-on techniques required short-term exposure of the $\mathrm{CuCl}$ to the atmosphere so there is still the possibility of some degradation before encapsulation. In addition, the relative thickness and probable lack of uniformity of spun-on films will be a drawback in device construction.

ALD is a chemical vapour deposition technique characterised by its ability to controllably deposit ultrathin layers with extreme uniformity. In ALD, the substrate is exposed sequentially to pulses of reactant gases or vapours and each pulse forms an additional chemisorbed molecular layer on it. Between the reactant pulses, an inert gas is used as a purge gas for removing all the excess precursor molecules that have not chemisorbed or undergone exchange reactions with the surface groups, and removing the reaction byproducts [21]. A single sequence of precursor and purge pulses is known as an ALD cycle. Initially, the film formation may proceed by the nucleation and growth of individual nanocrystallites, whose size and density varies according to the number of ALD cycles used in the process [22]. The details of this nucleation process are dependent on the chemical interaction between the precursors and the initial surface chemical state of the substrate, which is affected by its pretreatment. This process of controlled nucleation provides a possible method of producing plasmonic structures in copper halides in a much more repeatable way. In the previous ALD work $[18,19]$, the Cl precursor used, i.e., a solution of $\mathrm{HCl}$ in butanol, had limitations with respect to questionable stability of the vapour pressure and possible bi-reactions with butanol itself.

In this publication, we report on the sequentially pulsed chemical vapour deposition of $\mathrm{CuCl}$ using an alternative $\mathrm{Cl}$ precursor which circumvents the problems of the one used in previous ALD of $\mathrm{CuCl}$. We study the change in the distribution of nanocrystallites as deposition progresses. We characterise the structural, optoelectronic and chemical properties of the film and explore the use of ultrathin diffusion barrier layers deposited in situ to provide environmental protection.

\section{Materials and Methods}

The films were deposited simultaneously on quartz glass, Si, and soda-lime glass substrates by thermal pulsed chemical vapour deposition using a TFS 200 ALD system (Beneq Oy, Espoo, Finland). The deposition temperature and chamber pressure were $125{ }^{\circ} \mathrm{C}$ and 2 mbar, respectively, with 100, 200, 500, or 1000 deposition cycles. The precursor for copper was [Bis(trimethylsilyl)acetylene]-(hexafluoroacetylacetonato)copper(I) (Sigma-Aldrich, St. Louis, MO, USA), abbreviated to CuBTMSA for convenience heated to $80^{\circ} \mathrm{C}$, and the precursor for chlorine was pyridine hydrochloride (Sigma-Aldrich, $\geq 98 \%$ ) heated to $50{ }^{\circ} \mathrm{C}$. One $\mathrm{CuCl}$ deposition cycle was defined by the following sequence. Cu pulse (2 s) $\rightarrow \mathrm{N}_{2}$ purge (4s) $\rightarrow \mathrm{Cl}$ pulse (3s) $\rightarrow \mathrm{N}_{2}$ purge $(6 \mathrm{~s})$. Nitrogen was also used as a carrier gas. Some samples were protected against oxidation and atmospheric moisture by an $\mathrm{Al}_{2} \mathrm{O}_{3}$ capping layer. This capping layer was deposited in situ by ALD from trimethylaluminium (TMA, Strem Chemicals, Newburyport, MA, USA; electronic grade) and ozone (ozone generator, BMT Messtechnik, Stahnsdorf, Germany; $8 \mathrm{~g} / \mathrm{h}$ output) at $150{ }^{\circ} \mathrm{C}$. One $\mathrm{Al}_{2} \mathrm{O}_{3}$ ALD deposition cycle was defined by the following sequence. TMA pulse ( $0.1 \mathrm{~s}) \rightarrow \mathrm{N}_{2}$ purge (3s) $\rightarrow \mathrm{O}_{3}$ pulse (0.3 s) $\rightarrow \mathrm{N}_{2}$ purge (3 s). Ozone was used as the oxidiser here because of the fear that 
using water might hydrolyse the $\mathrm{CuCl}$. The capping layer consisted of $47 \mathrm{ALD}$ cycles giving an $\mathrm{Al}_{2} \mathrm{O}_{3}$ thickness of approximately $5 \mathrm{~nm}$. The deposition chamber was connected to a nitrogen glove box with moisture and oxygen content values $<0.1 \mathrm{ppm}$. The samples were stored in the glove box and only removed for the time necessary for analyses except for those capped samples deliberately exposed to the atmosphere.

ALD is characterised by growth saturation with increasing precursor dose and the presence of an ALD temperature window. In the process described here, the full range of deposition parameters has not yet been explored with these precursors to definitively prove that the $\mathrm{CuCl}$ deposition was purely an ALD process. Therefore, the process can only strictly be called sequentially pulsed chemical vapour deposition. We consider, however, that in comparing the growth of different samples it is in order to refer to the number of "ALD cycles" as a shorthand descriptor rather than saying "sequentially pulsed precursor-purge cycles".

The $\mathrm{CuCl}$ was deposited on various types of substrate: (i) silicon wafers (100) (P/Boron doped, thickness $=525 \pm 25 \mu \mathrm{m}, \Omega=10-30 \Omega \cdot \mathrm{cm}$ ); (ii) soda-lime glass; and (iii) quartz glass Herasil 102 (Heraeus, Hanau, Germany). Before the deposition the samples of size approximately $1 \times 1 \mathrm{~cm}^{2}$ were cleaned in an ultrasonic bath: $5 \mathrm{~min}$ in acetone, $5 \mathrm{~min}$ in isopropanol, and dried with nitrogen. Hydrofluoric acid was used to etch native oxide from the Si wafer surfaces. Transparent samples (soda-lime glass and quartz glass) were coated with Kapton tape on the back side to allow deposition only on one side. The Kapton tape was removed prior to optical measurements.

X-ray photoelectron spectroscopy (XPS) was carried out using an ESCALAB 250Xi apparatus (ThermoFisher Scientific, Waltham, MA, USA) with monochromated $\mathrm{Al} \mathrm{K} \alpha$ radiation $(1486.6 \mathrm{eV})$ to determine the chemical composition of $\mathrm{CuCl}$ thin films. All samples were measured at two spots at a takeoff angle of $90^{\circ}$ in $10^{-8}$ mbar vacuum at $20^{\circ} \mathrm{C}$. An electron flood gun was used to compensate for charges on sample surfaces. The spectra were referenced to $C-C$ at $284.8 \mathrm{eV}$. The spot size was $650 \times 650 \mu \mathrm{m}^{2}$ and the pass energy was $50 \mathrm{eV}$ for the survey and $20 \mathrm{eV}$ for the high resolution scan. The elemental composition was estimated from the survey spectra using Avantage ver. 5.938 software. The measurements on sample Q8 after atmospheric exposure were carried out using an Axis Supra instrument (Kratos Analytical, Manchester, UK) under slightly different conditions; spot size $700 \times 300 \mu \mathrm{m}^{2}$ and the pass energy was $120 \mathrm{eV}$ for the survey and $20 \mathrm{eV}$ for the high resolution scan. The analysis was done by CasaXPS software ver. 2.3.19PR1.0. The high-resolution spectra were fitted using XPSPEAK software (ver. 4.1) with Shirley and/or linear background.

Grazing incidence X-ray diffractometry (GIXRD) was used to measure the crystalline properties of the $\mathrm{CuCl}$. The measurements were taken with a SmartLab diffractometer (Rigaku, Tokyo, Japan) at grazing incidence angle $\alpha=0.2^{\circ}$ using a copper X-ray tube (1.542 $⿱$ ) $)$.

Normal-incidence reflectance was measured in the Vis-UV range using an Avantes 2048 pixel spectrometer (Avantes BV, Apeldoorn, The Netherlands; spectral range from 1.9 to $5.1 \mathrm{eV}$ ), equipped with a fibre reflectance probe [23]. The angles of incidence covered the range of $0.2^{\circ}-1.7^{\circ}$ and the nearly circular spot had a measured diameter of $0.8 \mathrm{~mm}$ for the $400 \mu \mathrm{m}$ detection fibre. The small measurement spot allowed us to test the in-plane homogeneity of the samples. Bare substrates were used to collect reference signals.

The photoluminescence (PL) data were obtained with using a LabRam HR Evolution (HORIBA Scientific, Kyoto, Japan) $0.8 \mathrm{~m}$ focal length single-stage spectrometer with CW HeCd laser excitation at $325 \mathrm{~nm}(3.8 \mathrm{eV})$. The mirror lens collected signals from approximately a $1 \mu \mathrm{m}$ circular spot; the excitation power was kept low enough to prevent heating of the layers $\left(\sim 200 \mathrm{~W} \mathrm{~cm}^{-2}\right)$. The PL spectra were recorded with a Peltier-cooled back-illuminated UV-sensitive CCD detector Synapse $2048 \times 512$. The instrument spectral range sensitivity has been corrected by the Intensity Correction System (HORIBA Scientific, Kyoto, Japan) delivered with the system. All reflectance and PL measurements were performed at room temperature $(300 \mathrm{~K})$. 


\section{Results and Discussion}

\subsection{Deposition}

Table 1 shows the deposition conditions for quartz glass samples.

The growth habit of the films on all substrates showed individual nuclei growing in number and size as the number of cycles increased. Figure 1 shows SEM images of the uncapped films on glass for 100, 200, 500, and 1000 ALD cycles (abbreviated to c. hereafter) deposited on soda-lime glass. The films on $\mathrm{Si}$ substrates were similar.

Table 1. Deposition parameters for films on quartz substrates.

\begin{tabular}{ccc}
\hline Sample No. & No. of ALD Cycles & Capping Layer \\
\hline Q1 & 100 & no \\
Q5 & 200 & no \\
Q7 & 500 & no \\
Q10 & 1000 & no \\
Q2 & 100 & yes \\
Q6 & 200 & yes \\
Q8 & 500 & yes \\
\hline
\end{tabular}

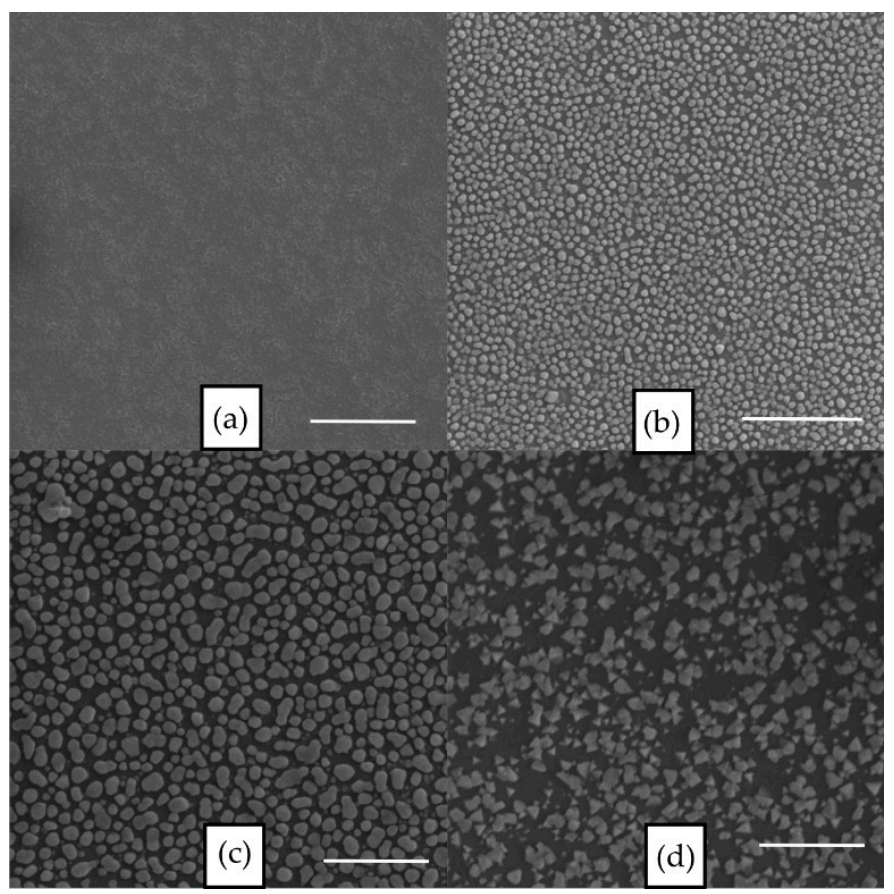

Figure 1. SEM images of $\mathrm{CuCl}$ deposited on soda-lime glass: (a) 100 c.; (b) 200 c.; (c) 500 c.; and (d) 1000 c. Scale bars represent $1 \mu \mathrm{m}$.

As the number of cycles increased, the diameter of the crystallites also increased. There was an initial nucleation phase and then the surface was covered in an array of crystallites. The areal density of the crystallites showed a decrease with the number of cycles; some form of agglomeration or ripening was evident. Dimensional change of the crystallites can take place by two processes: (i) Coalescence, where there is poor adhesion between the nanocrystallites and the substrate and they are mobile enough to move across it and to coalesce and (ii) Ostwald ripening, in which there is strong adhesion of the nanocrystallites to the surface and material transfer takes place by the diffusion of atoms across the surface. In this case, there is no significant coalescence of nanocrystallites therefore there is an Ostwald ripening process taking place. Initially, the crystallites had somewhat "liquid-like" 
shapes whereas the crystallites in the $1000 \mathrm{c}$. films had a more facetted appearance. This change in habit was accompanied by differences in the chemical composition of the films as discussed later. It is possible that this was caused by the longer deposition time required for the thicker film giving more time for reconfiguration of the crystallites. The size of the crystallites in the $\mathrm{CuCl}$ films increases with the number of cycles as shown in Figure 2a, while Figure $2 b$ shows this behaviour in comparison with that reported previously using different precursors [19].

Figure 2 demonstrates that the rate of increase of crystallite diameter is similar with both the current and the previous precursors, once the initial nucleation has taken place, and that the growth on crystalline and noncrystalline substrates is similar. This similarity is not unexpected since the reactant is $\mathrm{HCl}$ in both cases; here it is derived by decomposition of pyridine hydrochloride, previously the $\mathrm{HCl}$ vapour came from an $\mathrm{HCl} /$ butanol solution. The nucleation behaviour is somewhat different: with $\mathrm{PyrHCl}$ there is slower nucleation. However, with the $\mathrm{HCl} /$ butanol precursor the nucleation behaviour depended on the growth cycle parameters so further exploration of the deposition parameters with $\mathrm{PyrHCl}$ may also show differences in nucleation behaviour.

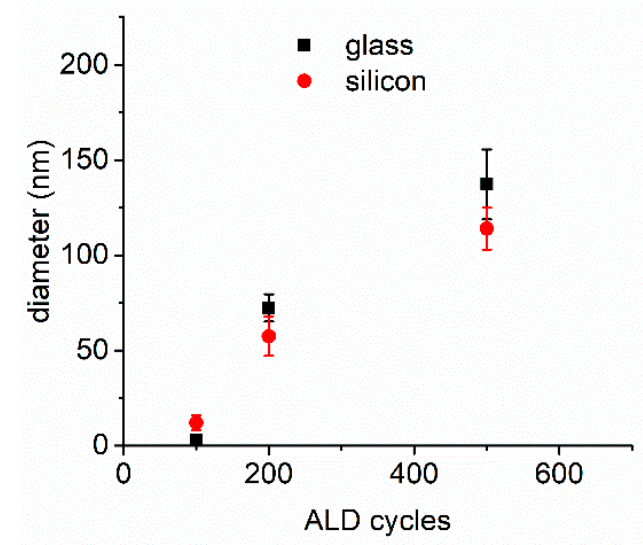

(a)

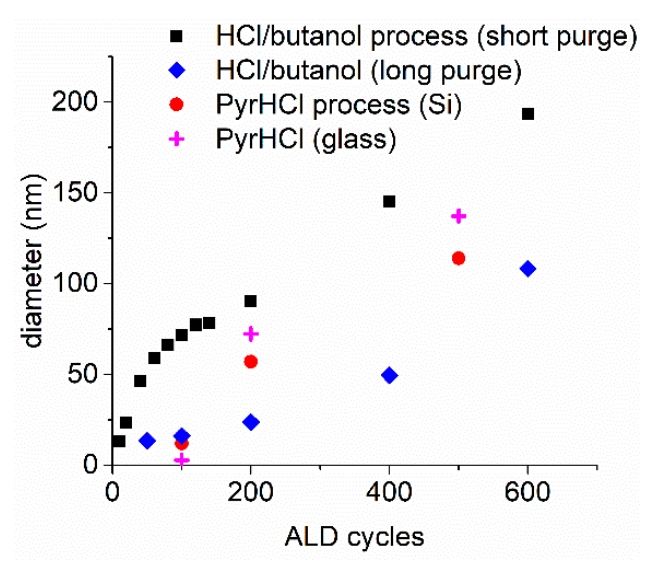

(b)

Figure 2. (a) Crystallite diameter vs. number of atomic layer deposition (ALD) cycles using pyridine hydrochloride $(\mathrm{PyrHCl})$ precursor and $(\mathbf{b})$ comparison with previous results using $\mathrm{HCl} /$ butanol as precursor $(\mathrm{HCl})$. $\bullet$ PyrHCl-Si, + PyrHCl-glass, $\mathbf{\square C l}$ (short purge), $\diamond \mathrm{HCl}$ (long purge). In (b) error bars have been omitted for clarity.

\subsection{Crystal Structure}

Films for XRD analysis were deposited on quartz glass both without a capping layer and with a capping layer of $\sim 5 \mathrm{~nm}$ of aluminium oxide deposited in situ in order to prevent the films undergoing hydrolysis in atmospheric moisture. The crystal structure was determined by X-ray diffraction (XRD) using GIXRD. The results are shown in Figure 3a,b. The films show the zinc blende crystal structure of $\gamma-\mathrm{CuCl}$ with no evidence of any other crystalline phases. The films with an $\mathrm{Al}_{2} \mathrm{O}_{3}$ capping layer also showed the same structure with small additional broad peaks at $\sim 36^{\circ}$ and $45^{\circ}$ (marked with asterisks). These do not fit $\mathrm{CuCl}_{2}$ (PDF 9001506), $\mathrm{CuO}$ (PDF 1011148), $\mathrm{Cu}_{2} \mathrm{O}$ (PDF 1010926), or other likely compounds. It is not clear what material they represent. The crystallites showed largely random orientation although with some preferential (220) orientation for thinner films. For randomly oriented films the intensity ratio $I_{220} / I_{111} \approx 0.60$ and the ratio here is much higher. However, it must be borne in mind that because of the glancing angle $\mathrm{X}$-ray incidence, any preferential orientation is not parallel to the substrate. From these results we can conclude that the bulk of the film is $\gamma-\mathrm{CuCl}$. 


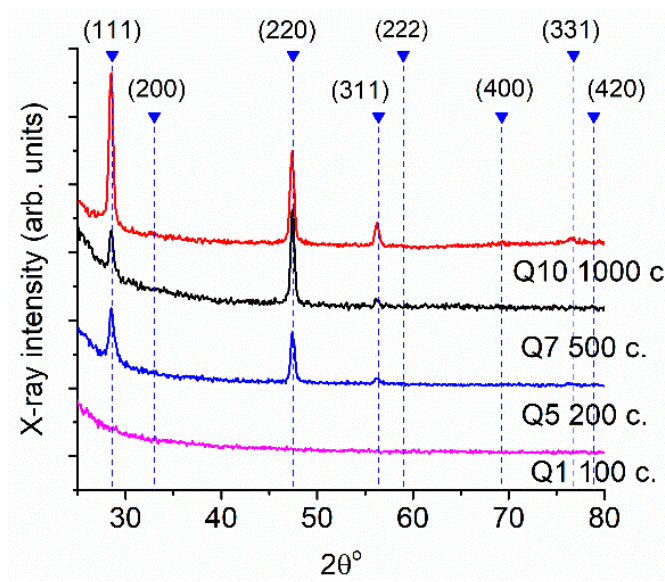

(a)

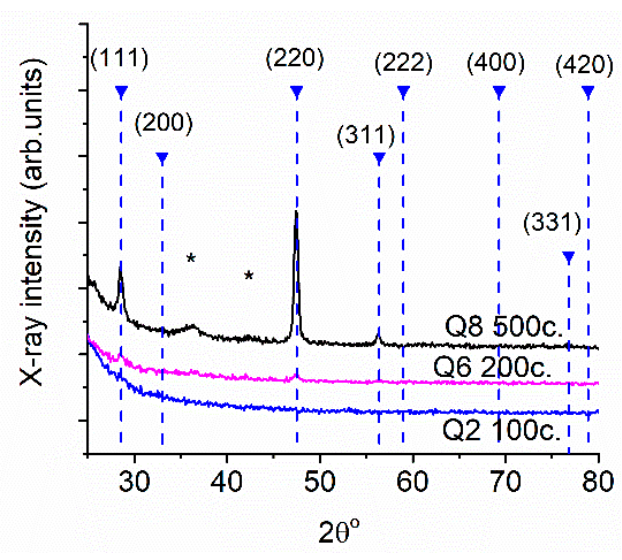

(b)

Figure 3. XRD spectra of (a) uncapped and (b) capped $\mathrm{CuCl}$ films on quartz substrates. Unidentified peaks marked with asterisks. Note: The "missing" CuCl peaks ((200), (222), (400), and (420)) have low intensities compared to the (111) peak for randomly oriented material (PDF 1010991).

\subsection{Chemical Composition}

The chemical composition was investigated by XPS. The scans were taken before and after Ar sputter-cleaning of the substrate to investigate the extent of surface contamination. Table 2 shows the analysis of survey scans of the deposited material for the unsputtered samples while Table 3 shows the relative concentrations of $\mathrm{Cu}$ and $\mathrm{Cl}$ after Ar sputter cleaning for $150 \mathrm{~s}$. The XPS analysis was not performed in situ so there will be significant amounts of adventitious carbon from environmental contamination between deposition and analysis for the unsputtered films. The sputtered samples show significantly reduced C 1 s signal. There is evidence, however, of the presence of carbon as a residue from the organic precursors (see below). There is also some fluorine content in all films which must come from the CuBTMSA precursor. There is significant uncertainty in the $\mathrm{Cu} / \mathrm{Cl}$ ration due to the dispersed crystallites which allow a large signal from the substrate material to be detected and because the relative sensitivity factor for the XPS quantification for the $\mathrm{Cl} 2 p$ peak is much lower than for the $\mathrm{Cu} 2 p$ peaks by a factor of $\sim 11$. Nevertheless, for the unsputtered samples the $\mathrm{Cu} / \mathrm{Cl}$ ratio is lower than the expected $1 / 1$ ratio for $\mathrm{CuCl}$; however, the sputter-cleaned samples show close to the stoichiometric ratio. The low $\mathrm{CuCl}$ ratio for the unsputtered samples arises from the different composition of the surface layer.

Table 2. Element concentration obtained from X-ray photoelectron spectroscopy (XPS) survey scan (not Ar-sputtered).

\begin{tabular}{ccccccccccc}
\hline \multirow{2}{*}{ Sample } & \multirow{2}{*}{ Cycles } & \multicolumn{8}{c}{ Concentration of Elements (at. \%) } \\
\cline { 3 - 12 } & & & Cu 2p & C1 2p & C 1s & Si 2p & A1 2p & O 1s & F 1s & Cu/Cl \\
\hline \multirow{4}{*}{ No cap } & Q1 & 100 & 0.5 & 3.1 & 19.6 & 29.9 & 0.0 & 46.6 & 0.4 & 0.1 \\
& Q5 & 200 & 1.9 & 2.7 & 12.9 & 31.3 & 0.0 & 50.5 & 0.7 & 0.7 \\
& Q7 & 500 & 1.4 & 2.7 & 15.7 & 31.1 & 0.0 & 48.6 & 0.5 & 0.5 \\
& Q10 & 1000 & 3.8 & 10.2 & 50.7 & 12.8 & 0.0 & 21.0 & 0.6 & 0.4 \\
\hline \multirow{3}{*}{ Capped } & Q2 & 100 & 0.3 & 0.8 & 22.1 & 8.4 & 21.9 & 46.3 & 0.3 & 0.3 \\
& Q6 & 200 & 0.2 & 0.5 & 23.9 & 6.0 & 23.2 & 45.7 & 0.4 & 0.4 \\
& Q8 & 500 & 0.2 & 0.7 & 25.9 & 5.5 & 24.0 & 43.5 & 0.3 & 0.3 \\
\hline
\end{tabular}


Table 3. Relative concentrations of $\mathrm{Cu}$ and $\mathrm{Cl}$ obtained from XPS (after Ar sputtering).

\begin{tabular}{ccccc}
\hline \multirow{2}{*}{ Sample } & \multirow{2}{*}{ Cycles } & \multicolumn{3}{c}{ Relative Concentration of $\mathbf{C u}$ and $\mathbf{C l}$} \\
\cline { 3 - 5 } & & $\mathbf{C u} \mathbf{2}$ & $\mathbf{C l ~} \mathbf{p}$ & $\mathbf{C u} / \mathbf{C l}$ \\
\hline Q7 & 500 & 55 & 45 & 1.2 \\
Q10 & 1000 & 49 & 51 & 1.0 \\
Q8 (capped) & 500 & 47 & 53 & 0.9 \\
\hline
\end{tabular}

High-resolution scans of the $\mathrm{Cl} 2 p$ peak from the uncapped samples with peak fittings are shown in Figure 4 for the unsputtered and sputter-cleaned samples. For Q1, Q5, and Q7 the $\mathrm{Cl} 2 p$ peak is well fitted by one $2 p$ doublet consisting of $2 p_{3 / 2}$ and $2 p_{1 / 2}$ components separated by $1.6 \mathrm{eV}$. Figure $4 \mathrm{a}$ is representative of these. The binding energy values are consistent with those given for copper chlorides although they cannot easily distinguish between $\mathrm{Cu}(\mathrm{I})$ and $\mathrm{Cu}(\mathrm{II})$ chloride. In general, the $\mathrm{CuCl}_{2}$ should appear at a higher binding energy [24-26]. Taking into account the XRD results which show only $\mathrm{CuCl}$ we conclude that peak at $\sim 199.0 \mathrm{eV}$ is $\mathrm{CuCl}$. There is no significant $\mathrm{ClO}_{x}$ formation: this would give rise to $2 p_{3 / 2}$ peaks at energies approximately $206-208 \mathrm{eV} \mathrm{[27],} \mathrm{and} \mathrm{there} \mathrm{is} \mathrm{no} \mathrm{evidence}$ of these in the $\mathrm{Cl} 2 p$ spectra. The peak details are given in Table 4. For sample Q10, if a single peak fitting is used, the fitting error is significantly higher. However, the measured Q10 signal can be well fitted with two $2 p$ components separated by $0.6 \mathrm{eV}$ (Figure $4 \mathrm{~b}$ ). This is consistent with the emergence of two different bonding environments for $\mathrm{Cl}$. The lower energy peak is characteristic of $\mathrm{HCl} \cdot n \mathrm{H}_{2} \mathrm{O}$ $(198.4 \mathrm{eV})$ [28] and is also consistent with $\mathrm{CuCl}$ bound to an organic ligand [29]. The peak area ratio between this component and the one at slightly lower energy is 1.4 indicating significant surface contamination. Figure $4 \mathrm{c}$ shows the $\mathrm{Cl} 2 p$ peak for Q7 after Ar sputter-cleaning. For the Ar-sputtered Q10 sample, again the best fit is with two doublets. In this case, the additional peak appears at higher energy, consistent with the existence of an organic chloride [28,30].

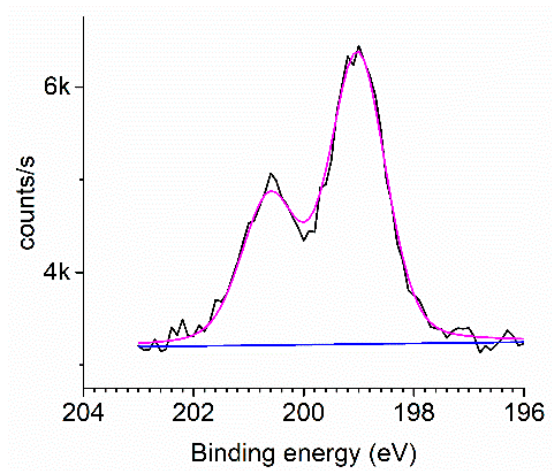

(a)

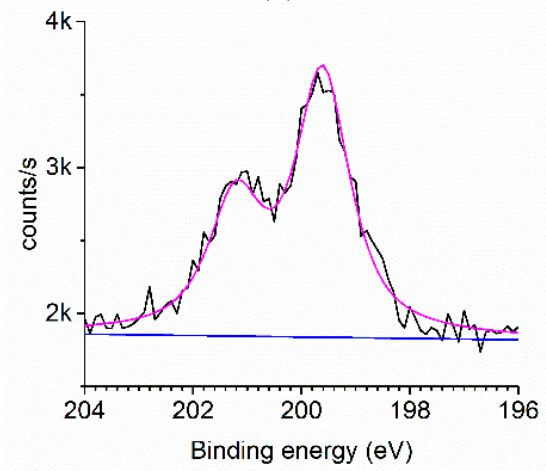

(c)

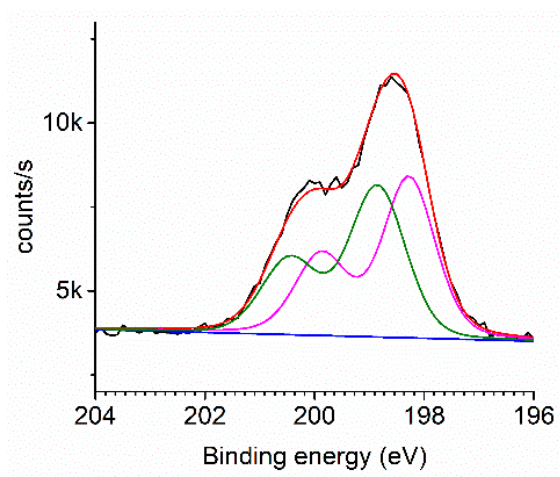

(b)

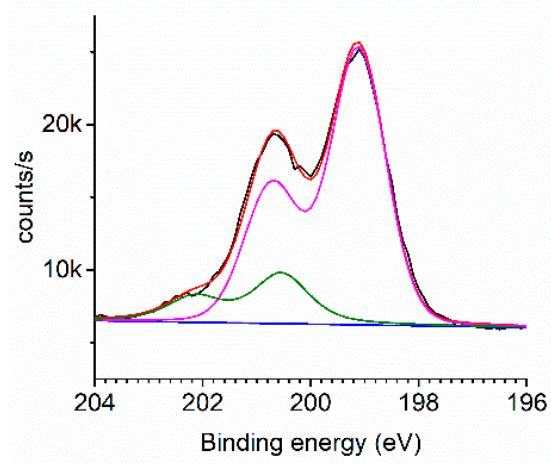

(d)

Figure 4. XPS Cl $2 p$ spectra for uncapped quartz samples showing fitted peaks: (a) Unsputtered Q7 500 c.; (b) unsputtered Q10 1000 c.; (c) Ar-sputtered Q7 500 c.; and (d) Ar-sputtered Q10 1000 c. 
Table 4. Components of $\mathrm{Cl} 2 p$ XPS peaks.

\begin{tabular}{|c|c|c|c|c|c|}
\hline Sample & Cycles & Peak & $2 p_{3 / 2}$ Binding Energy $(\mathrm{eV})$ & Area P2/P1 & Peak FWHM (eV) \\
\hline Q7, unsputtered & 500 & P1 & 199.0 & - & 1.2 \\
\hline Q7, Ar-sputtered & 500 & P1 & 199.6 & - & 1.2 \\
\hline \multirow{2}{*}{ Q10, unsputtered } & \multirow{2}{*}{1000} & P1 & 198.9 & \multirow{2}{*}{1.0} & 1.2 \\
\hline & & P2 & 198.3 & & 1.1 \\
\hline \multirow{2}{*}{ Q10, Ar-sputtered } & \multirow{2}{*}{1000} & P1 & 199.1 & \multirow{2}{*}{0.2} & 1.2 \\
\hline & & P2 & 200.5 & & 1.4 \\
\hline Q8 (capped), Ar-sputtered & 500 & P1 & 199.3 & - & 2.2 \\
\hline
\end{tabular}

Figure 5 shows the high resolution $2 p_{3 / 2}$ and $2 p_{1 / 2}$ raw data scans scan of $\mathrm{Cu}$ and the decomposition of the $2 p_{3 / 2}$ peaks into individual components. Q7 is representative of the other samples with less than $1000 \mathrm{c}$. deposition. Table 5 shows the peak positions and full width half maxima (FWHM).

It is difficult to separate the $\mathrm{Cu}^{0}, \mathrm{Cu}^{+}$, and $\mathrm{Cu}^{2+}$ peaks solely by their binding energies but taking into account the $\mathrm{XRD}$ spectra, peak $\mathrm{P} 1$ is assigned to $\mathrm{CuCl}$ which has been previously seen at 932.4-932.6 eV [31,32]. Peak P2 ( 934 eV) could be indicative of $\mathrm{CuO}, \mathrm{CuCl}_{2}$, or $\mathrm{Cu}$ with an organic or organo-chlorate ligand [33-36]. However, the presence of $\mathrm{Cu}^{2+}$ species should be indicated by an obvious shake-up satellite peak at $940 \mathrm{eV} \mathrm{[37]} \mathrm{and} \mathrm{there} \mathrm{is} \mathrm{no} \mathrm{evidence} \mathrm{of} \mathrm{this} \mathrm{in} \mathrm{Q7} \mathrm{both} \mathrm{with} \mathrm{and}$ without sputtering (Figure 5a,b). Neither is there evidence for chlorate bonding in the $\mathrm{Cl} 2 p$ spectra. Therefore, $\mathrm{Q} 7$ contains only $\mathrm{Cu}^{+}$bonds and $\mathrm{P} 2$ is ascribed to $\mathrm{Cu}(\mathrm{I})$ organic bonding. The amount of the $\mathrm{Cu}$ organic contamination in both Q7 and Q10 is clearly less after Ar sputtering (Figure 5d,f). Figure 5a,e, Q10 (1000 c., unsputtered), shows a large satellite peak at the expected energy for $\mathrm{Cu}^{2+}$ at $\sim 940 \mathrm{eV}$ together with a peak at $936.7 \mathrm{eV}, \mathrm{P} 3$, which may be evidence for some fluoride bound to organic material [38]. However, the Q10 Ar-sputtered sample, Figure 5f, shows the same three peaks as for the Q10 unsputtered sample with no evidence of a satellite peak. Therefore, it is not clear which of the peaks is related to the $\mathrm{Cu}^{2+}$ satellite peak. It may be that the relatively lower intensity of P3 after Ar sputtering gives rise to a much smaller satellite peak which is not visible in Figure $5 \mathrm{f}$.

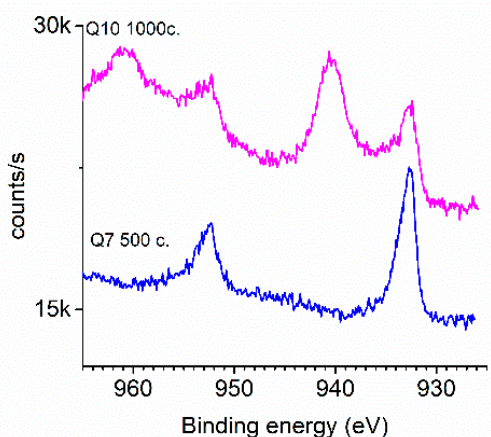

(a)

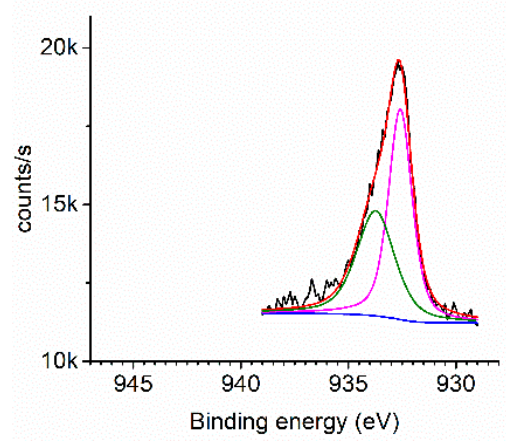

(c)

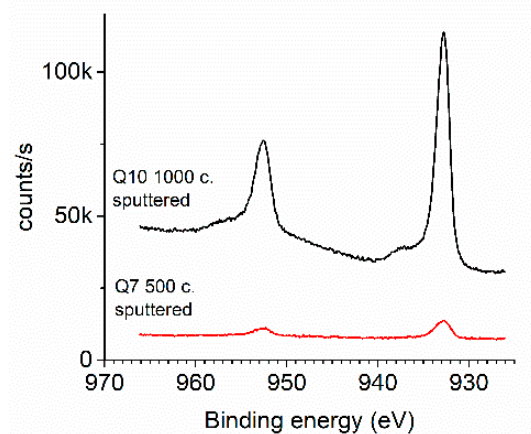

(b)

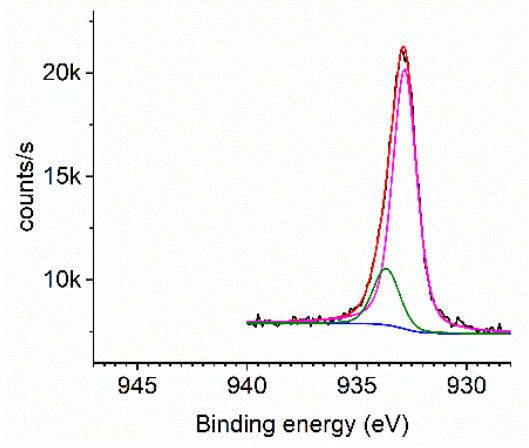

(d)

Figure 5. Cont. 


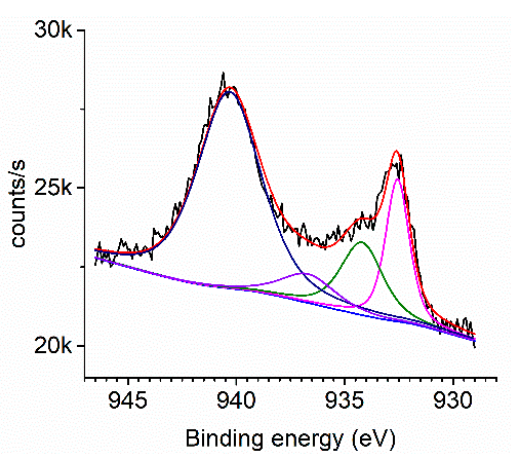

(e)

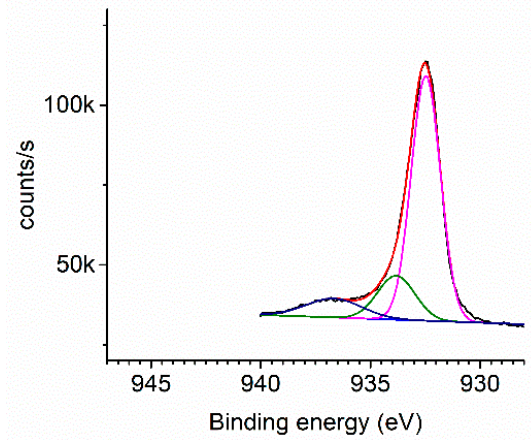

(f)

Figure 5. XPS Cu $2 p$ peaks, uncapped quartz samples: (a) Q7 500 c. and Q10 1000 c., unsputtered; (b) Q7 500 c. and Q10 1000 c., Ar-sputtered; (c) decomposed 2p $3 / 2$ peak, Q7, unsputtered; (d) decomposed $2 p_{3 / 2}$ peak, Q7, Ar-sputtered; (e) decomposed 2 $p_{3 / 2}$ peak, Q10, unsputtered; and (f) decomposed 2 $p_{3 / 2}$ peak, Q10, Ar-sputtered.

Table 5. Peak parameters for $\mathrm{Cu} 2 p$ XPS.

\begin{tabular}{cccccc}
\hline Sample & Cycles & Peak Cu $2 p_{3 / 2}$ & Binding Energy (eV) & FWHM & Assignment \\
\hline \multirow{2}{*}{ Q7, unsputtered } & \multirow{2}{*}{500} & P1 & 932.6 & 1.3 & $\mathrm{CuCl}$ \\
& & P2 & 933.7 & 2.1 & $\mathrm{Cu}(\mathrm{I})$ org. \\
\hline \multirow{2}{*}{ Q7, Ar-sputtered } & \multirow{2}{*}{500} & P1 & 932.8 & 1.3 & $\mathrm{CuCl}$ \\
& & P2 & 933.7 & 2.1 & $\mathrm{Cu}(\mathrm{I})$ org. \\
\hline \multirow{3}{*}{ Q10, unsputtered } & \multirow{2}{*}{1000} & P1 & 932.6 & 1.3 & $\mathrm{CuCl}$ \\
& & P2 & 934.2 & 2.3 & $\mathrm{Cu}(\mathrm{I})$ org. \\
& & P3 & 936.7 & 3.0 & organofluoride \\
\multirow{2}{*}{ Q10, Ar-sputtered } & \multirow{2}{*}{1000} & P1 & 940.3 & 3.5 & $\mathrm{Cu}^{2+}$ \\
& & P2 & 932.5 & 1.5 & $\mathrm{CuCl}$ \\
\multirow{2}{*}{ Q8, Ar-sputtered } & \multirow{2}{*}{500} & P3 & 933.8 & 2.0 & $\mathrm{Cu}(\mathrm{I})$ org. \\
& & P1 & 936.7 & 3 & organofluoride \\
\hline
\end{tabular}

Observation of the $\mathrm{O} 1 s$ spectra yields further information. The spectra for Q7 and Q10 before and for Q10 after Ar sputtering are shown in Figure 6. The samples are dominated by the peak at $533.3 \mathrm{eV}$ due to $\mathrm{SiO}_{2}$ [39] from the quartz since the substrate coverage is not complete. Both unsputtered samples, Figure $6 \mathrm{a}, \mathrm{b}$, also show a peak at $\sim 534 \mathrm{eV}$ which is probably $\mathrm{O}$ in an organic ligand indicating some residual CuBTMSA precursor material in the film. In addition, Figure $6 \mathrm{~b}$ shows a large additional peak at $535.8 \mathrm{eV}$, which is at an energy which has been ascribed to an $\mathrm{O}$ atom linked to a CF containing ligand [30]. This again is likely due to some partially decomposed CuBTMSA precursor. Figure $6 \mathrm{c}$ is representative of all the sputtered samples and shows only the $\mathrm{SiO}_{2}$ peak indicating that the oxygen bonded to organic material is only on the surface.

When the $\mathrm{Cl} 2 p, \mathrm{Cu} 2 p$, and $\mathrm{O} 1 s$ results are taken together with the XRD results, it is clear that the bulk of the films consists of $\gamma-\mathrm{CuCl}$ with a certain amount of organic contamination from the precursor molecules. This is confirmed by the presence of significant carbon content even in the Ar-sputtered samples. The unsputtered samples show, as is to be expected, greater organic contamination, including from F-containing organic fragments and $\mathrm{HCl}$ from the $\mathrm{CuBTMSA}$ and $\mathrm{PyrHCl}$ precursors, respectively. The exact nature of the bonding is the subject of further investigation. 


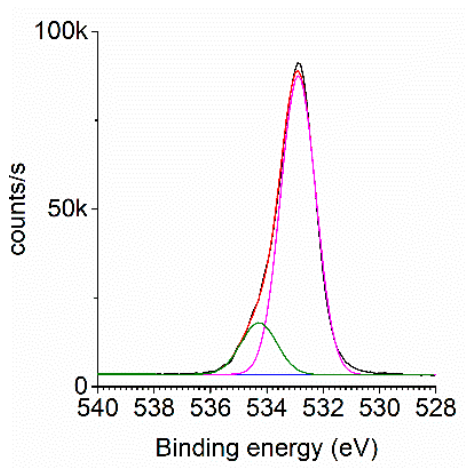

(a)

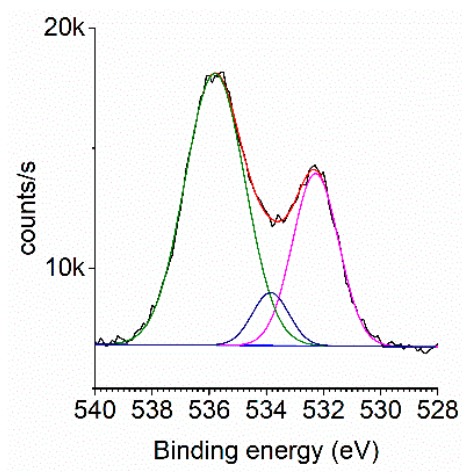

(b)

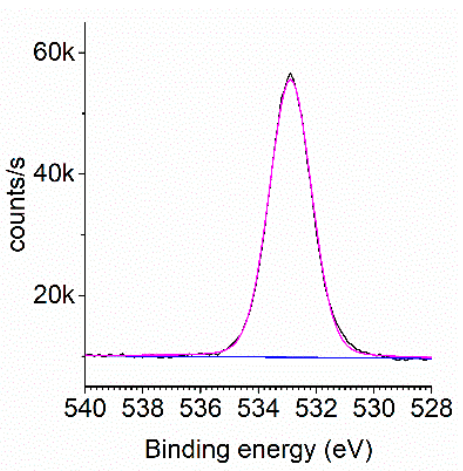

(c)

Figure 6. Decomposition of $\mathrm{O} 1 \mathrm{~s}$ peaks for uncapped quartz samples: (a) Q7 500 c., unsputtered; (b) Q10 1000 c., unsputtered; and (c) Q10 1000 c., Ar-sputtered.

Thin uncapped $\mathrm{CuCl}$ films will hydrolyse after approximately one day. Figure 7 and Tables 3-5 show measurements on the sputter cleaned sample Q8 (500 c., $\mathrm{Al}_{2} \mathrm{O}_{3}$ capped) after exposure to normal atmosphere for approximately 3 weeks. The curves and tabulated data are very similar to those of the uncapped samples with the same number of growth cycles kept in an inert atmosphere (Figures $4 \mathrm{c}$ and $5 \mathrm{e}$ ). They show no evidence of degradation, indicating that $5 \mathrm{~nm}$ of oxide capping layer provides an effective barrier to hydrolysis of the films.

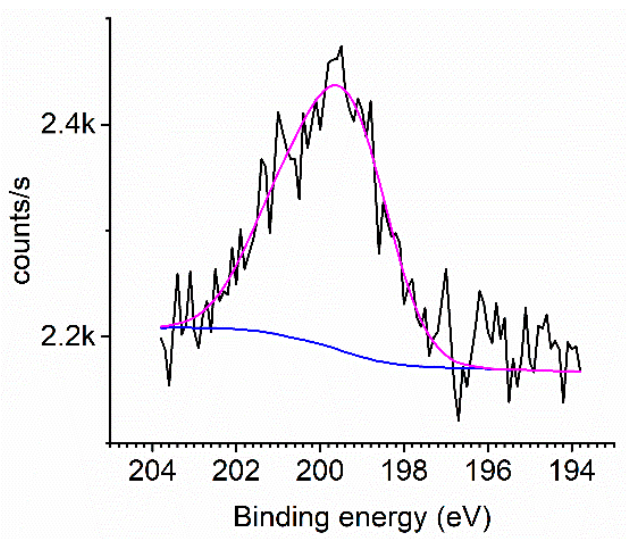

(a)

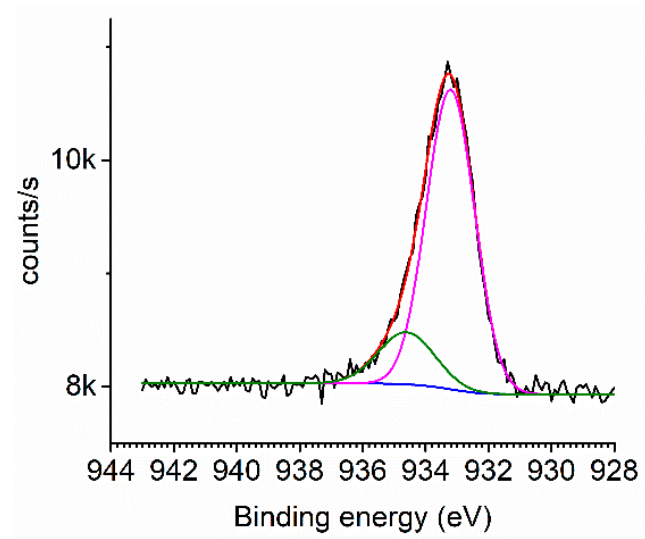

(b)

Figure 7. Decomposition of (a) $\mathrm{Cl} 2 p$ and (b) Cu 2p $3 / 2$ peaks of Q8 (500 c. capped, Ar-sputtered) after approximately 3 weeks in normal air.

\subsection{Photoluminescence}

The photoluminescence signals obtained from sample Q10 (1000 c., uncapped) were easily measurable at room temperature. Shown in Figure 8 is the experimental spectrum, decomposed into three Gaussian bands located on a linear background. The sum fits the measured data within background noise. The band parameters are listed in Table 6. We use band area as the measure of its strength. The location of the PL maximum is very close to the position of the strongest PL2 band, coinciding with the position of the absorption peak PL2 $(3.248 \mathrm{eV})$ of Table 6 within experimental uncertainty. The weaker but discernible high-energy PL3 band at $3.308 \mathrm{eV}$ lies $0.06 \mathrm{eV}$ above PL2. The lower energy band PL1 is situated at $3.225 \mathrm{eV}$, approximately $0.10 \mathrm{eV}$ lower than PL2. These results are similar to those observed on $\mathrm{CuCl}$ films obtained by thermal evaporation [40] and magnetron sputtering [41]. Those showed that at low temperature the emission peak could be resolved into three components which broadened into one composite peak at room temperature. The main peak was identified as the $Z_{3}$ free exciton peak observed at energy $3.227 \mathrm{eV}$ at $15 \mathrm{~K}$. This peak shifted to higher energy of $3.243 \mathrm{eV}$ at room temperature, a shift of approximately $0.016 \mathrm{eV}$ [42]. This peak is 
almost at the same energy as the main peak reported here $(3.248 \mathrm{eV})$. The peak shown here can also be decomposed into three components. By comparison with these results and allowing for the shift with temperature, the main peak indicating the most probable radiative channel is ascribed to the $Z_{3}$ exciton. The lower energy peak we see at $3.225 \mathrm{eV}(385.4 \mathrm{~nm})$ can be ascribed to the $I_{1}$ peak due to an exciton bound to an impurity, probably a Cu vacancy [43]. The higher energy peak at $3.308 \mathrm{eV}(375.8 \mathrm{~nm})$ can be ascribed to the $Z_{1,2}$ exciton. PL mapping across the sample shown in Figure $9\left(32 \times 32 \mu \mathrm{m}^{2}\right.$, step $4 \mu \mathrm{m}$ ) shows intensity varying by a factor of approximately 2 , due to local variations of the effective film thickness. No changes in peak position, width or shape were observed.

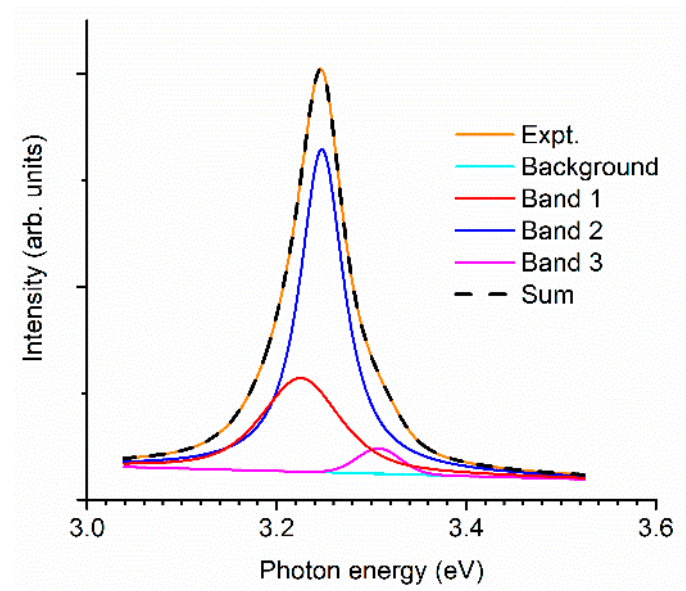

Figure 8. Photoluminescence emission intensity vs. photon energy showing resolved peaks for Q10 (1000 c. uncapped sample). The dashed line is the fitted peak.

Table 6. Best-fit parameters of the Gaussian bands used in modelling the PL spectrum of Figure 8.

\begin{tabular}{cccc}
\hline Band & Strength (a.u.) & Position (eV) & Width (eV) \\
\hline PL1 & $5.8 \pm 0.3$ & $3.225 \pm 0.010$ & $0.097 \pm 0.010$ \\
PL2 & $13.1 \pm 0.3$ & $3.248 \pm 0.010$ & $0.056 \pm 0.010$ \\
PL3 & $0.7 \pm 0.3$ & $3.308 \pm 0.010$ & $0.054 \pm 0.02$ \\
\hline
\end{tabular}

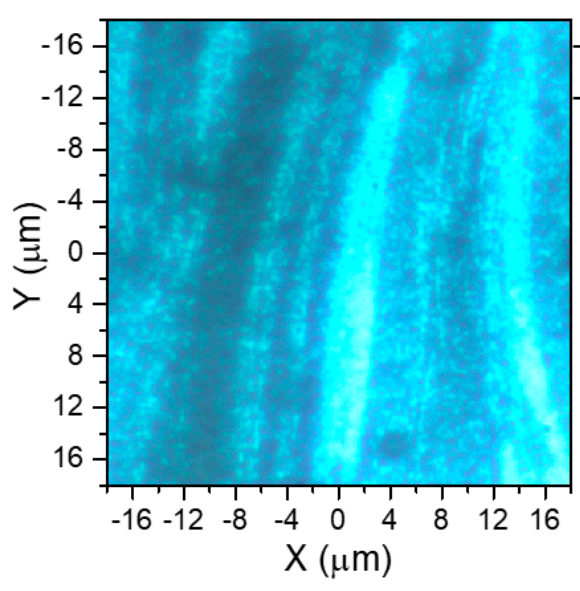

(a)

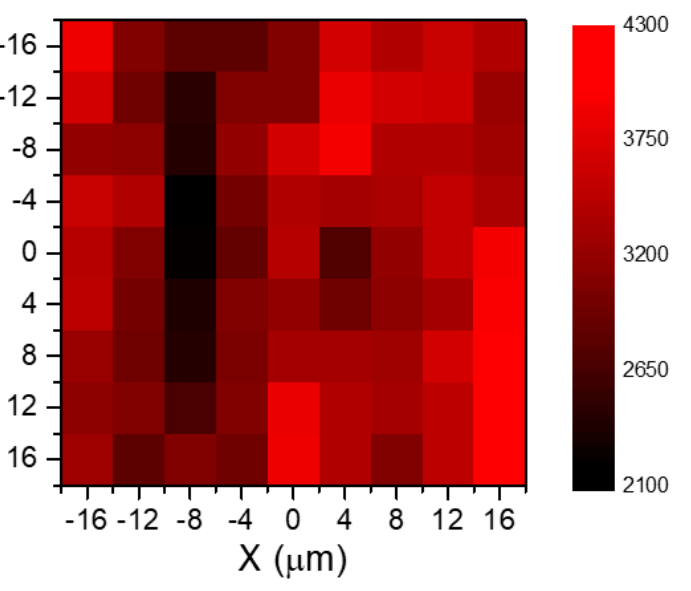

(b)

Figure 9. Uncapped quartz sample Q10, 1000 c. (a) White light photography and (b) integral PL intensity (arb. units) over the same area of the substrate with $4 \times 4 \mu \mathrm{m}^{2}$ resolution.

\subsection{Reflectance}

The measured reflectance spectrum of the thickest uncapped $\mathrm{CuCl}$ film (Q10 $1000 \mathrm{c}$.) is shown in Figure 10a. It shows a significant increase of the reflected intensity compared to the bare substrate, 
which is indicative of a larger optical density of the film. In addition, a fairly strong spectral structure with maximum intensity at about $3.3 \mathrm{eV}$ has apparently at least two narrow components. The latter are better seen in the twice differentiated spectra plotted in Figure 10b. The differentiation enhances the sharper structures and suppresses the flat background. Based on the narrow structures in the derivative spectra, we have fitted the measured reflectance with a model consisting of a flat background dielectric function, with two superposed Gaussian absorption bands. The model lineshape of Figure 10a,b represents the best-fit results with the (fitted) value of the film thickness of $29 \mathrm{~nm}$, and the background value of the real part of its dielectric function of 3.2. The resulting parameters of the bands are listed in Table 7. The strength parameter is proportional to the area below the absorptive (imaginary) part of the dielectric function, having the units of $\mathrm{eV}$; however, we are interested in relative values and use arbitrary units here.

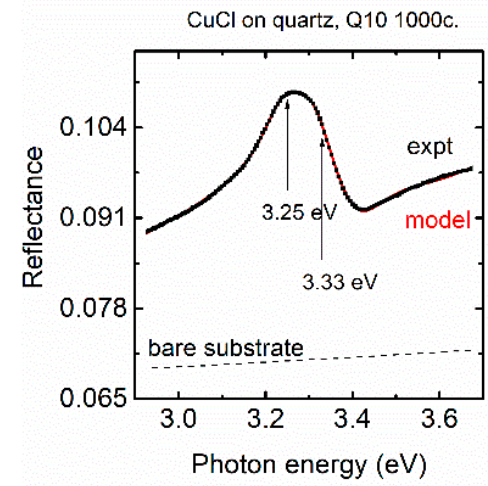

(a)

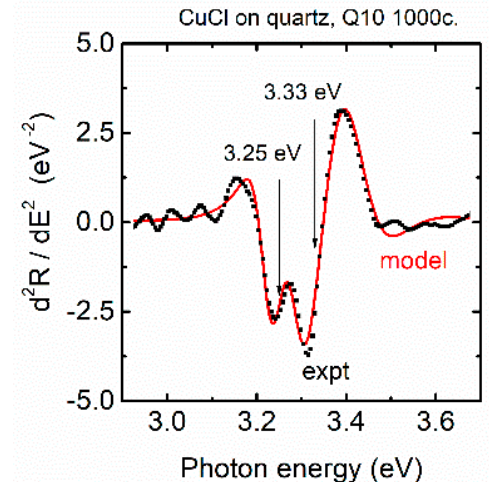

(b)

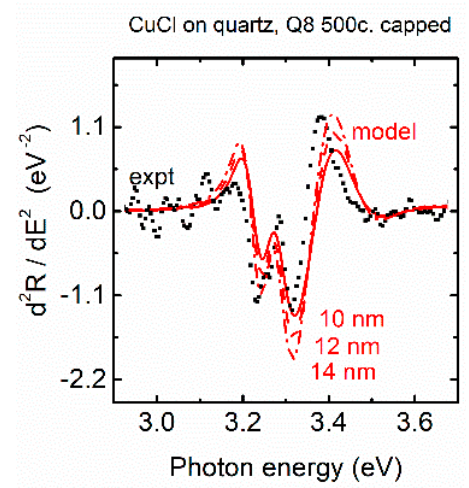

(c)

Figure 10. (a) Normal incidence reflectance spectra of the uncapped, 1000 c. sample; the positions of two prominent Gaussian bands are indicated by arrows, bare substrate (dashed line); (b) second derivative; and (c) second derivative of the reflectance spectrum from the capped, $500 \mathrm{c}$. sample. Measured data (symbols), model lineshapes (red solid and dashed lines).

Table 7. Best-fit parameters of the Gaussian bands used in modelling the reflectance spectra of Figure 10.

\begin{tabular}{cccc}
\hline Band & Strength (a.u.) & Position (eV) & Width (eV) \\
\hline R1 & $0.03 \pm 0.01$ & $3.25 \pm 0.01$ & $0.06 \pm 0.02$ \\
R2 & $0.23 \pm 0.01$ & $3.33 \pm 0.01$ & $0.14 \pm 0.02$ \\
\hline
\end{tabular}

The two Gaussian bands are $0.08 \mathrm{eV}$ apart, which is in a good agreement with the distance of $0.06 \mathrm{eV}$ seen in the absorption spectra of $Z_{3}(3.23 \mathrm{eV})$ and $Z_{1,2}(3.308 \mathrm{eV})$ excitons at in the PL results and those seen at $4 \mathrm{~K}$ [44]. In addition, the significantly larger strength of the upper ( $3.30 \mathrm{eV})$ band is clearly seen in the reflectance results, in contrast to the PL intensities. This is similar to the relative intensities seen in direct optical absorption measurements $[18,45]$. We have also observed a weak and broad luminescence band centred at about $2.7 \mathrm{eV}$, with the maximum signal below $4 \%$ of the main PL band; its high energy tail forms the smooth background seen in Figure 7. This may be due to radiative recombination of defect states in the $\mathrm{CuCl}$ crystallites, as well as other species present in the deposited layer.

A film of the sample Q8 (500 c. with an $\mathrm{Al}_{2} \mathrm{O}_{3}$ capping layer) displays a reduced intensity excitonic structure in the differentiated reflectance, see Figure 10c. The results are compatible with reduced effective film thickness of approximately $12 \mathrm{~nm}$. In addition, the upper lineshape seems to be narrower than that of the thicker sample Q10, probably due to the smaller dispersion of the crystallite sizes. It can be seen that reflectance measurements are a useful way to identify the presence of $\mathrm{CuCl}$ in thin films. This method would be particularly useful where the film is deposited on a non-UV transparent substrate. 
The reflectance of sample Q8 was remeasured after approximately three weeks in normal atmosphere. A comparison between the two measurements is shown in Figure 11. There is no significant change to the excitonic absorption confirming the XPS results that $5 \mathrm{~nm}$ of $\mathrm{ALD} \mathrm{Al}_{2} \mathrm{O}_{3}$ provides an effective protection layer for the $\mathrm{CuCl}$. This is consistent with published work showing that $\mathrm{ALD} \mathrm{Al}_{2} \mathrm{O}_{3}$ constitutes a good moisture diffusion barrier when applied to other materials [46].

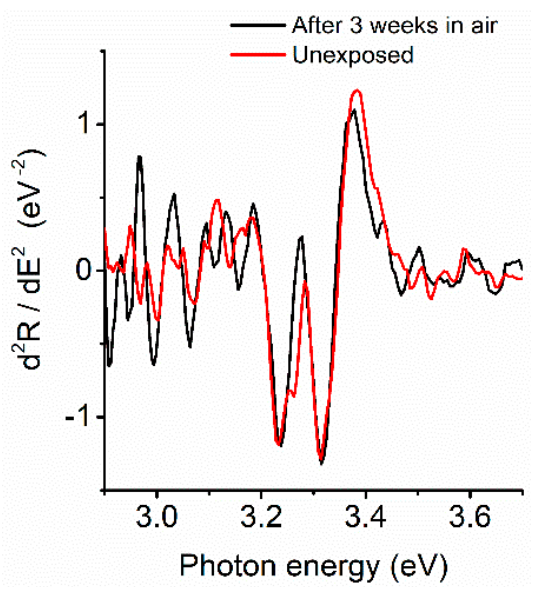

Figure 11. Comparison of reflectance curves (2nd derivative) for aluminium oxide-capped sample Q8 before and after approximately 3-week exposure to ambient air.

\section{Conclusions}

It has been demonstrated that $\mathrm{CuCl}$ can be deposited by sequentially pulsed vapour deposition process using the precursors [Bis(trimethylsilyl)acetylene](hexafluoroacetylacetonato)copper(I) and pyridine hydrochloride and that an in situ ALD capping layer of aluminium oxide is an effective barrier for preventing atmospheric degradation. The crystal structure has been shown to be the zinc blende-structure $\gamma-\mathrm{CuCl}$ by XRD. The crystallites become more facetted as the film thickness increases. The bulk of films shows only some organic contamination from incomplete precursor reaction, however, there is heavier organic contamination on the surface, again from unreacted precursor molecules. The characteristic photoluminescence behaviour of $\mathrm{CuCl}$ has been shown with emissions from the $Z_{1,2}, Z_{3}$ and bound excitons. The chemical composition was investigated by XPS: the $200 \mathrm{c}$. and $500 \mathrm{c}$. films show surface layers with predominantly $\mathrm{Cu}^{+}$bonding from $\mathrm{CuCl}$ with some organic contamination. The thicker films with 1000 deposition cycles have significant $\mathrm{Cu}^{2+}$ content from $\mathrm{CuF}_{2}$ or $\mathrm{F}$ containing organic fragments. Optical reflectance measurements have shown that the characteristic exciton absorptions can be detected, at similar energies to optical absorption features measured by transmission. This enables exciton absorption measurements to be carried out on nontransparent samples.

The overall results show that this is a method for deposition of nanocrystalline arrays suitable for further investigation for the development of new optoelectronic structures and devices. Further studies are also required to clarify the difference in chemical composition between the surface layers and the bulk of the film.

Author Contributions: Conceptualization, D.C.C; Methodology, D.C.C.; Formal Analysis, T.H., R.K., and D.C.C.; Investigation, R.K., T.H., O.C., K.K., R.Z., J.P., and J.M.M.; Resources, R.Z., J.P., and J.M.M.; Writing-Original Draft Preparation, T.H. and J.H.; Writing-Review \& Editing, D.C.C., J.H., R.Z., J.M.M., R.K., T.H., K.K., and O.C.; Visualization, D.C.C. and J.H.; Supervision, D.C.C., J.H., and J.M.M.; Project Administration, D.C.C. and R.K.; Funding Acquisition, D.C.C. and J.M.M.

Funding: This work was financially supported by the Czech Science Foundation (No. 17-02328S), the Ministry of Youth, Education and Sports of the Czech Republic (Nos. LM2015082, LQ1601, LO1411 (NPU I), and CZ.02.1.01/0.0/0.0/16_013/0001829), and the European Regional Development Fund (project CZ.1.05/2.1.00/03.0086). 
Acknowledgments: The authors acknowledge the support of COST action MP1402 HERALD in the course of this work.

Conflicts of Interest: The authors declare no conflicts of interest.

\section{References}

1. Soga, M.; Imaizumi, R.; Kondo, Y.; Okabe, T. A method of growing $\mathrm{CuCl}$ single crystals with flux. J. Electrochem. Soc. 1967, 114, 388-390. [CrossRef]

2. Nakayama, M.; Ichida, H.; Nishimura, H. Bound-biexciton photoluminescence in $\mathrm{CuCl}$ thin films grown by vacuum deposition. J. Phys. Cond. Matter 1999, 11, 7653-7662. [CrossRef]

3. Monemar, B. Fundamental energy gap of GaN from photoluminescence excitation spectra. Phys. Rev. B 1974, 10, 676. [CrossRef]

4. Ryu, Y.R.; Lee, T.S.; White, H.W. Properties of arsenic-doped-type ZnO grown by hybrid beam deposition. Appl. Phys. Lett. 2003, 83, 87-89. [CrossRef]

5. Alam, M.M.; Lucas, F.O.; Danieluk, D.; Bradley, A.L.; Daniels, S.; McNally, P.J. Temperature dependent photoluminescence of nanocrystalline $\gamma$-CuCl hybrid films. Thin Solid Films 2014, 564, 104-109. [CrossRef]

6. Alam, M.M.; Lucas, F.O.; Danieluk, D.; Bradley, A.L.; Rajani, K.V.; Daniels, S.; McNally, P.J. Hybrid organic-inorganic spin-on-glass $\mathrm{CuCl}$ films for optoelectronic applications. J. Phys. D Appl. Phys. 2009, 42, 225307. [CrossRef]

7. Göbel, A.; Ruf, T.; Cardona, M.; Lin, C.T.; Wrzesinski, J.; Steube, M.; Reimann, K.; Merle, J.C.; Joucla, M. Effects of the isotopic composition on the fundamental gap of CuCl. Phys. Rev. B 1998, 57, 15183. [CrossRef]

8. Mitra, A.; O’Reilly, L.; Lucas, O.F.; Natarajan, G.; Danieluk, D.; Bradley, A.L.; McNally, P.J.; Daniels, S.; Cameron, D.C.; Reader, A.; Martinez-Rosas, M. Optical properties of $\mathrm{CuCl}$ films on silicon substrates. Phys. Status Solidi B 2008, 245, 2808-2814. [CrossRef]

9. Grun, J.B.; Hönerlage, B.; Levy, R. Dynamics of optical nonlinearities and bistability in 3-level systems $(\mathrm{CuCl})$. Phys. Scr. 1986, T13, 184-188. [CrossRef]

10. Gomes, M.; Kippelen, B.; Hönerlage, B. Time, intensity and energy dependence of four-wave mixing processes in CuCl. Phys. Stat. Solidi B 1990, 159, 101-106. [CrossRef]

11. Natarajan, G.; Daniels, S.; Cameron, D.C.; O’Reilly, L.; Mitra, A.; McNally, P.J.; Lucas, O.; Rajendra Kumar, R.T.; Reid, I.; Bradley, A.L. Stoichiometry control of sputtered $\mathrm{CuCl}$ thin films: Influence on ultraviolet emission properties. J. Appl. Phys. 2006, 100, 033520. [CrossRef]

12. Kawamori, A.; Edamatsu, K.; Itoh, T. Growth of $\mathrm{CuCl}$ nanostructures on $\mathrm{CaF}_{2}(111)$ substrates by $\mathrm{MBE}-\mathrm{Their}$ morphology and optical spectra. J. Cryst. Growth 2002, 237-239, 1615-1619. [CrossRef]

13. O’Reilly, L.; Lucas, O.F.; McNally, P.J.; Reader, A.; Natarajan, G.; Daniels, S.; Cameron, D.C.; Mitra, A.; Martinez-Rosas, M.; Bradley, A.L. Room-temperature ultraviolet luminescence from $\gamma$-CuCl grown on near lattice-matched silicon. J. Appl. Phys. 2005, 98, 113512. [CrossRef]

14. Zhou, Y.Y.; Lu, M.K.; Zhou, G.J.; Wang, S.F. Preparation and photoluminescence of gamma-CuI nanoparticles. Mater. Lett. 2006, 60, 2184-2186. [CrossRef]

15. Kurisu, H.; Nagoya, K.; Nakayama, N.; Yamamoto, S.; Matsura, M. Exciton and biexciton properties of $\mathrm{CuCl}$ microcrystals in an $\mathrm{SiO}_{2}$ matrix prepared by sputtering method. J. Lumin. 2000, 87-89, 390-392. [CrossRef]

16. Fukumi, K.; Chayahara, A.; Kageyama, H.; Kadono, K.; Akai, T.; Mizoguchi, H.; Horino, Y.; Makihara, M.; Fujii, K.; Hayakawa, J. Formation process of $\mathrm{CuCl}$ nano-particles in silica glass by ion implantation. J. Non-Cryst. Sol. 1999, 259, 93-99. [CrossRef]

17. Yingjie, Z.; Yitai, Q.; Youfou, C. $\gamma$-Radiation synthesis of nanocrystalline powders of copper (I) halides. Mater. Sci. Eng. B 1999, 57, 247-250. [CrossRef]

18. Natarajan, G.; Maydannik, P.S.; Cameron, D.C.; Akopyan, I.; Novikov, B.V. Atomic layer deposition of CuCl nanoparticles. Appl. Phys. Lett. 2010, 97, 241905. [CrossRef]

19. Maydannik, P.S.; Natarajan, G.; Cameron, D.C. Atomic layer deposition of nanocrystallite arrays of copper(I) chloride for optoelectronic structures. J. Mater. Sci.-Mater. Electron. 2017, 28, 11695-11701. [CrossRef]

20. Lucas, O.; O’Reilly, L.; Natarajan, G.; McNally, P.J.; Daniels, S.; Taylor, D.M.; William, S.; Cameron, D.C.; Bradley, A.L.; Mitra, A. Encapsulation of the heteroepitaxial growth of wide bandgap-CuCl on silicon substrates. J. Cryst. Growth 2006, 287, 112-117. [CrossRef] 
21. George, S.M.; Ott, A.W.; Klaus, J.W. Surface chemistry for atomic layer growth. J. Phys. Chem. 1996, 100, 13121-13131. [CrossRef]

22. Cameron, D.C.; Krumpolec, R.; Ivanova, T.V.; Homola, T.; Černák, M. Nucleation and initial growth of atomic layer deposited titanium oxide determined by spectroscopic ellipsometry and the effect of pretreatment by surface barrier discharge. Appl. Surf. Sci. 2015, 345, 216-222. [CrossRef]

23. Humlíček, J.; Šik, J. Optical functions of silicon from reflectance and ellipsometry on silicon-on-insulator and homoepitaxial samples. J. Appl. Phys. 2015, 118, 195706. [CrossRef]

24. Sesselmann, W.; Chuang, T.J. The interaction of chlorine with copper: I. Adsorption and surface reaction. Surf. Sci. 1993, 176, 32-66. [CrossRef]

25. Vasquez, R.P. CuCl by XPS. Surf. Sci. Spect. 1993, 2, 138-143. [CrossRef]

26. Vasquez, R.P. $\mathrm{CuCl}_{2}$ by XPS. Surf. Sci. Spect. 1993, 2, 160-164. [CrossRef]

27. Martin-Vosshage, D.; Chowdari, B.V.R. XPS Studies on $(\mathrm{PEO})_{n} \mathrm{LiCIO}_{4}$ and $(\mathrm{PEO})_{n} \mathrm{Cu}\left(\mathrm{CIO}_{4}\right)_{2}$ polymer electrolytes. J. Electrochem. Soc. 1995, 142, 1442-1446. [CrossRef]

28. Wren, A.G.; Phillips, R.W.; Tolentino, C.U. Surface-reactions of chlorine molecules and atoms with water and sulfuric-acid at low-temperatures. J. Colloid Interface Sci. 1979, 70, 544-557. [CrossRef]

29. Yamamoto, Y.; Konno, H. Ylide-metal complexes. X. An X-ray photoelectron spectroscopic study of triphenylmethylenephosphorane and gold- and copper-phosphorane complexes. Bull. Chem. Soc. Jpn. 1986, 59, 1327-1330. [CrossRef]

30. Beamson, G.; Briggs, D. High Resolution XPS of Organic Polymers: The Scienta ESCA300 Database; Wiley: New York, NY, USA, 1992.

31. Klein, J.C.; Proctor, A.; Hercules, D.M.; Black, J.F. X-ray excited Auger intensity ratios for differentiating copper-compounds. Anal. Chem. 1983, 55, 2055-2059. [CrossRef]

32. Wagner, C.D. Chemical-shifts of auger lines, and Auger parameter. Faraday Discuss. Chem. Soc. 1975, 60, 291-300. [CrossRef]

33. Ressan, M.; Furlani, C.; Polzonetti, G. XPS of coordination-compounds-Additive ligand effect in some copper(I) and copper(II) chelates with 1,2 phosphino (or phosphine oxide)-sulfido ethane ligands. Polyhedron 1983, 2, 523-528. [CrossRef]

34. Parmigiani, F.; Depero, L.E.; Minerva, T.; Torrance, J.B. The fine-structure of the Cu $2 p_{3 / 2}$ X-ray photoelectron-spectra of copper-oxide based compounds. J. Electron. Spectrosc. Relat. Phenom. 1992, 58, 315-323. [CrossRef]

35. Kishi, K.; Ikeda, S. X-ray photoelectron spectroscopic study of the reaction of evaporated metal films with chlorine gas. J. Phys. Chem. 1974, 78, 107-112. [CrossRef]

36. Li, X.; Liu, Z.; Kim, J.; Lee, J-Y. Heteogeneous catalytic reaction of elemental mercury vapor over cupric chloride for mercury emissions control. Appl. Catal. B Environ. 2013, 132-133, 401-407. [CrossRef]

37. Biesinger, M.C.; Lau, L.W.M.; Gerson, A.R.; Smart, R.S.C. Resolving surface chemical states in XPS analysis of first row transition metals, oxides and hydroxides: Sc, Ti, V, Cu and Zn. Appl. Surf. Sci. 2010, 257, 887-898. [CrossRef]

38. Van der Laan, G.; Westra, C.; Haas, C.; Sawatzky, G.A. Satellite structure in photoelectron and auger-spectra of copper dihalides. Phys. Rev. B 1981, 23, 4369. [CrossRef]

39. Finster, J.; Klinkenberg, E.-D.; Heeg, J.; Braun, W. ESCA and SEXAFS investigations of insulating materials for ULSI microelectronics. Vacuum 1990, 41, 1586-1589. [CrossRef]

40. O'Reilly, L.; Natarajan, G.; McNally, P.J.; Cameron, D.; Lucas, O.F.; Martinez-Rosas, M.; Bradley, L.; Reader, A.; Daniels, S. Growth and characterisation of wide-bandgap, I-VII optoelectronic materials on silicon. J. Mater. Sci. Mater. Electron. 2005, 16, 415-419. [CrossRef]

41. Natarajan, G.; Mitra, A.; O’Reilly, L.; Daniels, S.; Cameron, D.C.; McNally, P.J.; Lucas, O.F.; Bradley, L. Optical investigations on sputtered $\mathrm{CuCl}$ thin films. In Progress in Semiconductor Materials $V$ : Novel Materials and Electronic and Optoelectronic Applications, Proceedings of the MRS Symposium, Boston, MA, USA, 28 November-1 December 2005; Olafsen, L.J., Biefeld, R.M., Wanke, M.C., Saxler, A.M., Eds.; Cambridge University Press: New York, NY, USA, 2006; pp. 151-156.

42. Natarajan, G.; Mitra, A.; Daniels, S.; Cameron, D.C.; McNally, P.J. Temperature dependent optical properties of UV emitting $\gamma-\mathrm{CuCl}$ thin films. Thin Solid Films 2008, 516, 1439-1442. [CrossRef]

43. Certier, M.; Wecker, C.; Nikitine, S. Zeeman effect of free and bound excitons in CuCl. J. Phys. Chem. Sol. 1969, 30, 2135-2142. [CrossRef] 
44. Cardona, M. Optical properties of the silver and cuprous halides. Phys. Rev. 1963, 129, 69-78. [CrossRef]

45. Akopyan, I.K.; Golubkov, V.V.; Dyatovla, O.A.; Novikov, B.V.; Tsagan-Mandzhiev, A.N. Structure of copper halide nanocrystals in photochromic glasses. Phys. Solid State 2008, 50, 1352-1356. [CrossRef]

46. Carcia, P.F.; McLean, R.S.; Walls, D.J.; Reilly, M.H.; Wyre, J.P. Effect of early stage growth on moisture permeation of thin-film $\mathrm{Al}_{2} \mathrm{O}_{3}$ grown by atomic layer deposition on polymers. J. Vac. Sci. Technol. A 2013, 31, 061507. [CrossRef]

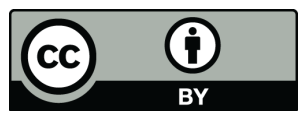

(C) 2018 by the authors. Licensee MDPI, Basel, Switzerland. This article is an open access article distributed under the terms and conditions of the Creative Commons Attribution (CC BY) license (http:/ / creativecommons.org/licenses/by/4.0/). 